\title{
Recognition and Distinction of Hydrological Relations of Tashk and Bakhtegan Lakes Using GIS \& RS Techniques
}

\author{
Dr. Sayyed Ali Almodarresi* \\ PhD Geomorphology, Assistant Professor, Civil Engineering College, GIS \& RS Department, \\ Yazd Branch, Islamic Azad University, Hesabi Blv, Safaeie, Yazd, Iran \\ Soleyman Zare \\ M.A Student, Civil Engineering College, GIS \& RS Department, \\ Yazd Branch, Islamic Azad University, HesabiBIv,Safaeie, Yazd, Iran \\ Dr. Mostafa Khabazi \\ Assistant Professor in Department of Geography, \\ ShahidBahonar University of Kerman, Kerman, Iran
}

Doi:10.5901/mjss.2014.v5n23p2732

\section{Abstract}

Lakes as close ecosystems on the earth which have special patterns and hydrological relationships in lakes can determine the development or reduction trends of lake ranges, attachment or detachment between them, lakes water balance and also the changes and fluctuations in water regimes, during the time. Therefore, the Tashk and Bakhtegan lakes were studied, based on the regional climate studies and identification the droughness and wetness years, multi-spectral satellite images using the LANDSAT satellite (including the OLI, ETM+, ETM and MSS sensing images) and IRS during the years 1979_2013. Were used and analyzed and also the lake water level fluctuations during different periods were determined. Based on all used models from lakesin studied period, the hydrological relationship between lakes were proved, and the effects of climatic factors and in the stage after that, the effects of geomorphological factors as detachment factors for Bakhtegan and Tashklaked were determined.

Keywords: Bakhteganand Tashklakes, hydrological relationships,modeling, GIS, RS

\section{Introduction}

Some natural forms and phenomenons on earth, arechanged, affected by internal or erosion events of external earth crust very slowly and some are changed very fast, so that some of these changes are observable during the human life. The important point is that ,these changes should be studied correctly with the aim of natural processes or human factors identification which cause these changes (Singh,1989). Lakes as the close ecosystems on earth have special patterns and hydrological forms which determination these changes and hydrological relationships detection in lakes can determine the development or reduction trends of lake, attachment or detachment between them, lake water balance and also the changes and fluctuations in water regimes during the time. On the other hand, for optimal shore's management and environment protection in line with sustainable development, we need theshore lines extraction and determination the lakes ranges and limits as quaternary climatic evidences.So the aim of present study was to evaluate the share lines changes in Bakhtegan and Tashk lakes and also modeling and following the hydrological evidences of these lakes during the time.

\section{Research history}

Ting _ ping_sing et.al (1998) were evaluated and determined the shore lines of Tunel _ sup lake in Thailand. They used the topographical maps and, hydrological data and also by analyzing the satellite images, provided the studied region shore line maps and drawded(traced) the shore line's maps during the droughness and wetness periods.

Stephen Kish(2005) studied the water level balance of Chekson and Florida lakes based on climatic elements 
(evaporation and precipitation) and also using the remote sensing technology and GIS. The results showed that the water level fluctuations of mentioned lake can be determined using the remote sensing technology correctly, during theinvestigationperiod.

Seyf (2005) have done his evaluation and paleogeomorphological analysis of Gaw-Khooni region using the remote sensing and GIS. In his research, using an innovative method, the Gaw-Khooni ranges were reconstructed in 4 different intrusion and retrogration phases and after the ranges identification, separation and superposition using the Paleogeomorphological forms such as alluvial fans, lake terraces and Deltas around the past phases, the geomorphological descriptive data were provided.

Dr.MohammadSharifi-Kia (2010) in an article, with the title, Investigation the water balance changes in Hamoon lakes, based on time series analysis of remote sensing images, compared the Hamoon lake impoundment grounds during two time periods, the years 1976 and 2005 , with equal water level and using the connected vessles law. He analyzed the LANDSAT Satellite images during, 30 years period to detect the water level changes.

Khabbazi(2013) in his doctoral thesis, evaluated and detected the hydrological relationships between Qom and Dagh - sorkh lakes in Iran's central parts using the remote sensing and GIS technology.

Therefore, withattention to the Bakhtegan and Tashk lakes importance and the hydrological relationships between them .the water level around mentioned lakes were studied using the time series satellite images, topographicalmaps and the regional numerical models.

\section{Geographical characters and position}

\subsection{Bakhtegan and Tashk lakes hydrological basin}

The Tashk and Bakhtegan hydrological basin are placed in Fars province northern region and in eastern ranges of Zagros southern parts. The mentioned area is placed between geographical coordinates $51^{\circ} 42^{\prime}$ until $54^{\circ} 31^{\prime}$ eastern longtitude and $29^{\circ}$ - $00^{\prime}$ until $31^{\circ}$. $14^{\prime}$ northern altitude. This region total area is equal to $27047 \mathrm{~km} 2$, which approximately $49 / 92 \%$ of that is composed the hilly regions and $50 / 06 \%$ is composed from the rangelands and valleys. The basin maximum height is equal to 3910/81 meters in north _ western of basin and the minimum height is equal to 1476 meters in Tashk lake depths.

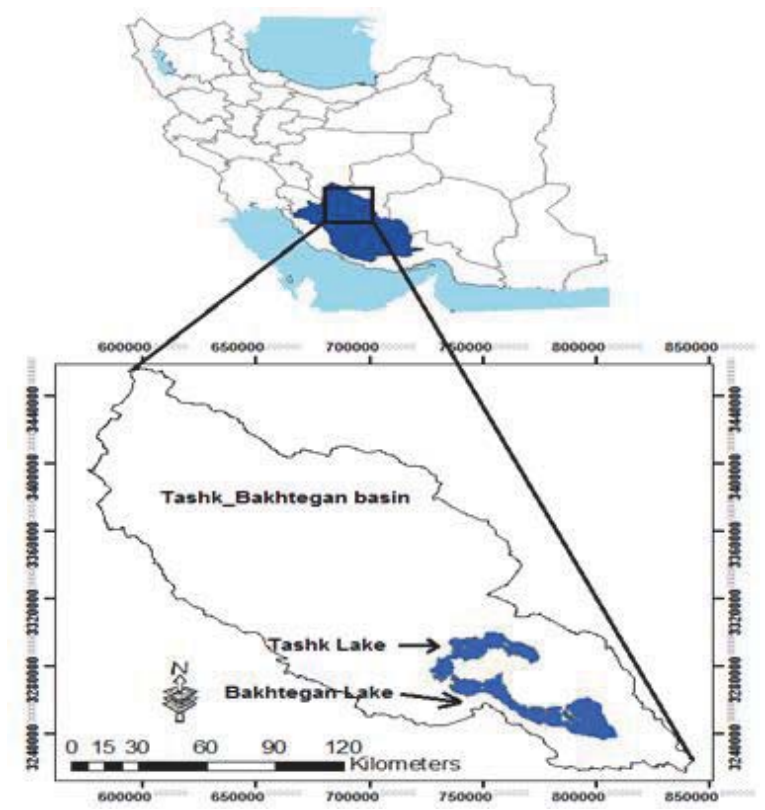

Figure 1: The Tashk_Bakhtegan basin geographical position. 


\subsection{Bakhtegan Lake}

The Bakhtegan Lake is placed in east _ southern part of the basin and in the southern part of Tashk Lake. This lake is placed between geographical longtitudes $53^{\circ}{ }_{-} 25^{\prime}$ until $54^{\circ}$ 10' eastern degree and the geographical widths $29^{\circ}{ }_{-} 15^{\prime}$ until $29^{\circ}$ 33 northern degree. With attention to lake's morphōogical measurements based on satellite images in the year 1976, the lake total area is equal to $796 / 48 \mathrm{~km} 2$. The most important and water determinatorfactor, is the Kor river which begins from the basin western mountains and down hills to this lake.

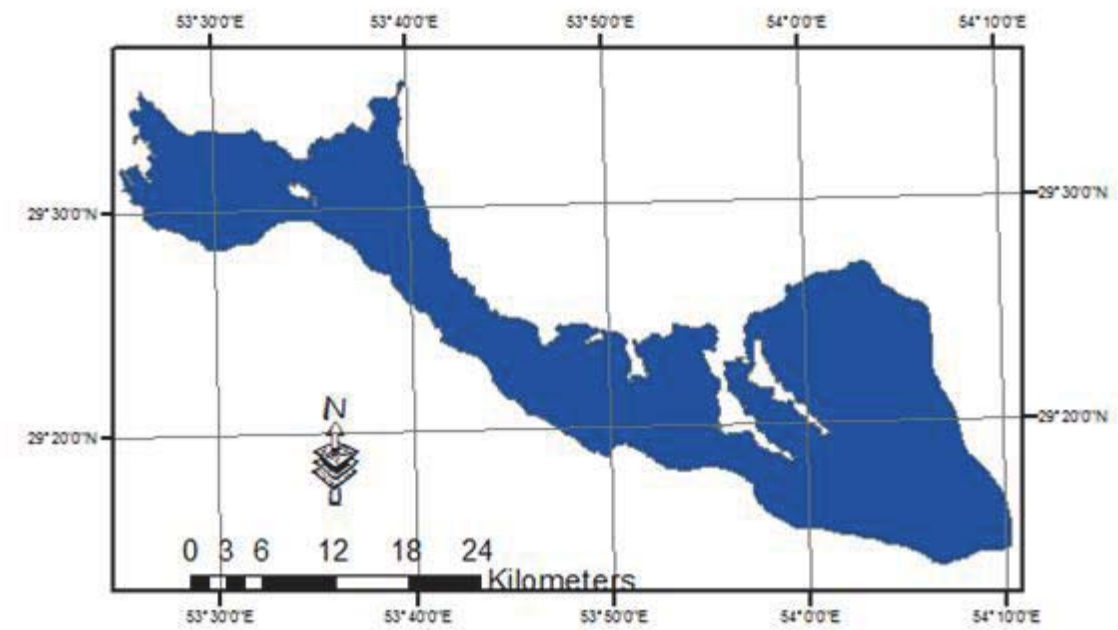

Figure 2: The Bakhtegan lake geographical position.

\subsection{Tashk Lake}

The Tashk Lake is placed in basin's south _ eastern part and in the north of Bakhtegan Lake, which is placed between geographical longtitudes $53^{\circ} 20^{\prime}$ until $53^{\circ}{ }_{-} 50^{\prime}$ eastern degree and geographical widths $29^{\circ} 30^{\prime}$ until $29^{\circ} 5^{\prime}$ northern degree. Based on satellite images of the year 1976, this lake total area is equal to $455 / 72 \mathrm{~km} 2$. In addition to the korriver, the Gomban spring in Norther Lake's part is an important determinator of this lake water conditions.

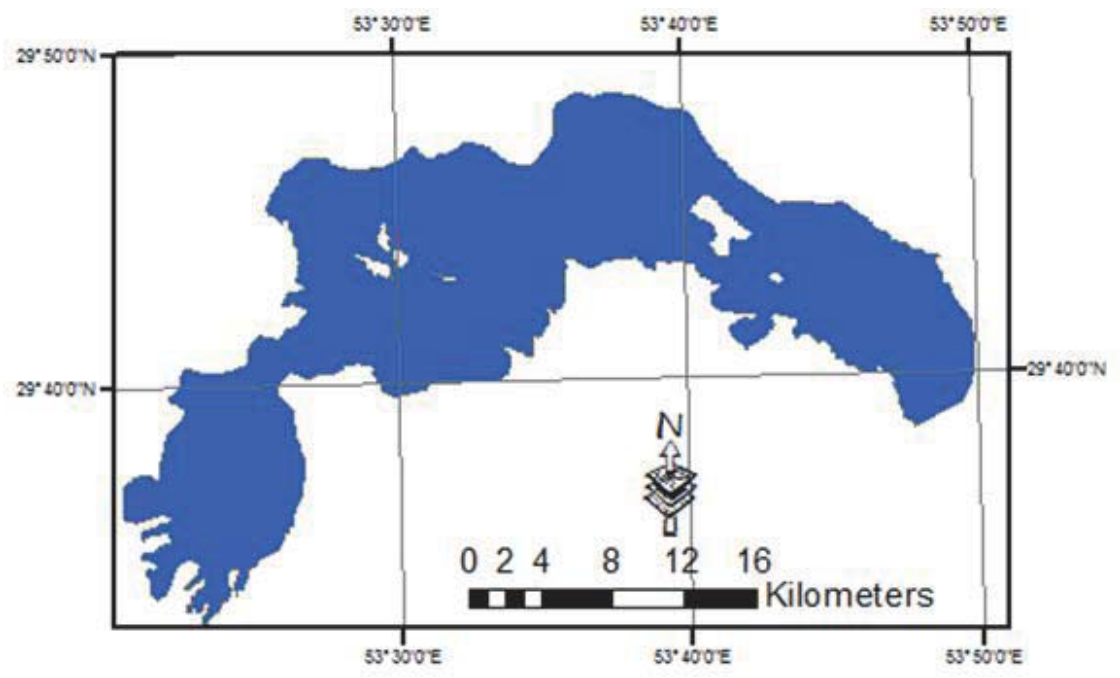

Figure 3: The Tashk lake geographical position. 


\section{Data and methods}

The aim of present research was to investigate the hydrological relationships between Tashk and Bakhtegan lakes based on connected vessles law using the remote sensing and GIS technology. So we selected the data sets of remote sensing using the LANDSAT satellite and the MSS , ETM , ETM+ , OLI sensors and the IRS satellite related to the years 1976 A.D until the 2013 A.D. All geometrical and radiometricneeded corrections for all images were done in ENVI 4/8 software environment. For geometrical correction operations, the terrestrial control points were used which adopted by topographical maps in scale 1/25000 and UTM coordinates. Because of studied place extent, the satellite images were putted in many sheets so in each stage, the time series analyses of Bakhtegan and Tashk lakes were composed using the mosaic _ making method. Using the data of this stage and climatic data from the studied region in mentioned timeperiod, the water regime determination of Bakhtegan and Task lakes and grouping the wet,drough and usual years was done. To determine the water level and lake's water space and comparing them with other years (the year 1976 A.D)(the MSS sensing images) regarded as wet basal year. In the following , after studing the present geomorphological factors in studied region and tracing the Tashk and Bakhtegan statistical changes using GIS and RS method and procedures, tracing the Bakhtegan and Tashklakes's water level and old shore lines reconstruction of mentioned lakes was done.The hydrological relationships between these lakes based on connected vessles law was proved. Therefore the climatic and geomorphological factors importance including the unevenness between Tashk and Bakhtegan lakes in detachment part of them were determined.
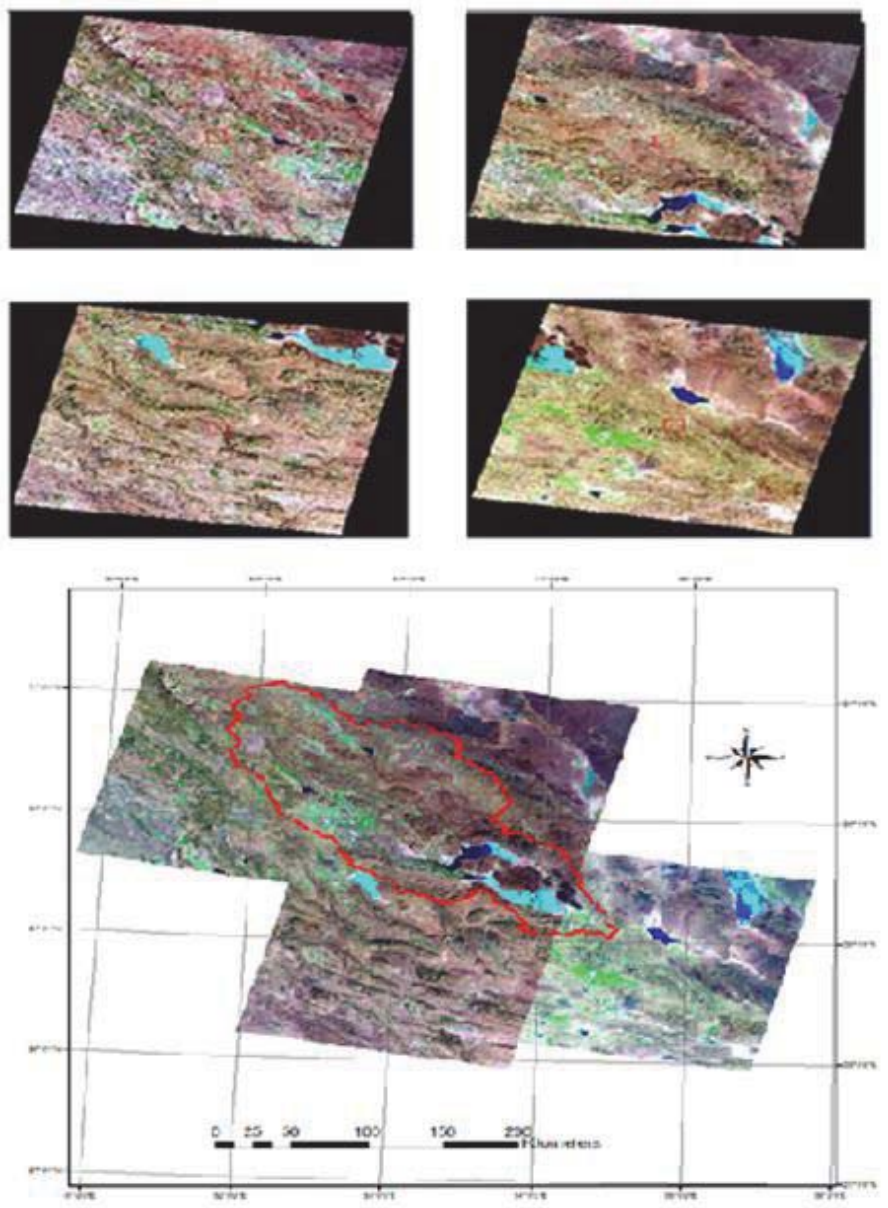

Figure 4: Cutting and mosaic images of the study area 


\section{Findings}

Based on mentioned satellite images, the vectoral maps from Tashk and Bakhtegan impoundment areas were prepared and their morphological characters were measured which are shown in figures 1 , and 2. So, the lake ranges and area reduction and their detachment were determined obviously.

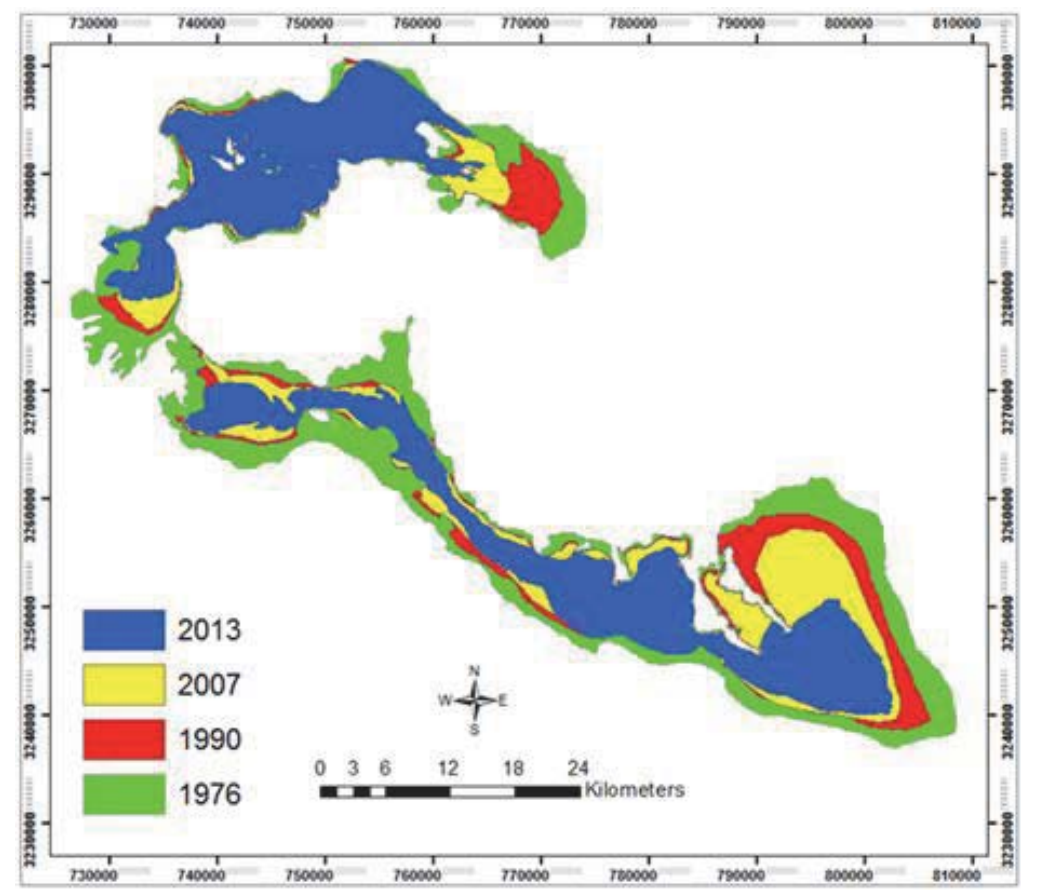

Figure 5: the Bakhtegan and Tashk lakes water level changes during the years 1976_2013

Table 1: The Tashk lake area changes

\begin{tabular}{|c|c|c|}
\hline Year & Area & Water volume \\
\hline 1976 A.D & $455 / 72 \mathrm{Km} 2$ & $713377045516 \mathrm{~m} 3$ \\
\hline 1990 A.D & $350.37 \mathrm{Km} 2$ & $556649219670 \mathrm{~m} 3$ \\
\hline 2007 A.D & $305.41 \mathrm{Km} 2$ & $489327693890 \mathrm{~m} 3$ \\
\hline 2013 A.D & $263.15 \mathrm{Km} 2$ & $408749083436 \mathrm{~m} 3$ \\
\hline
\end{tabular}

Table 2: The Bakhtegan lake area changes:

\begin{tabular}{|c|c|c|}
\hline Year & Area & Water volume \\
\hline 1976 A.D & $796.48 \mathrm{Km} 2$ & $1254426826422 \mathrm{~m} 3$ \\
\hline 1990 A.D & $535.97 \mathrm{Km} 2$ & $833016875485 \mathrm{~m} 3$ \\
\hline 2007 A.D & $443.52 \mathrm{Km} 2$ & $688801501590 \mathrm{~m} 3$ \\
\hline 2013 A.D & $300.31 \mathrm{Km} 2$ & $465193673008 \mathrm{m3}$ \\
\hline
\end{tabular}

Based on the area networking file (DEM), the hydrological relationship between these two lakes were determined and reconstructed level equal to 1565 meters. This relationship is shown in three dimensional space on satellite imagen in figure 6. 


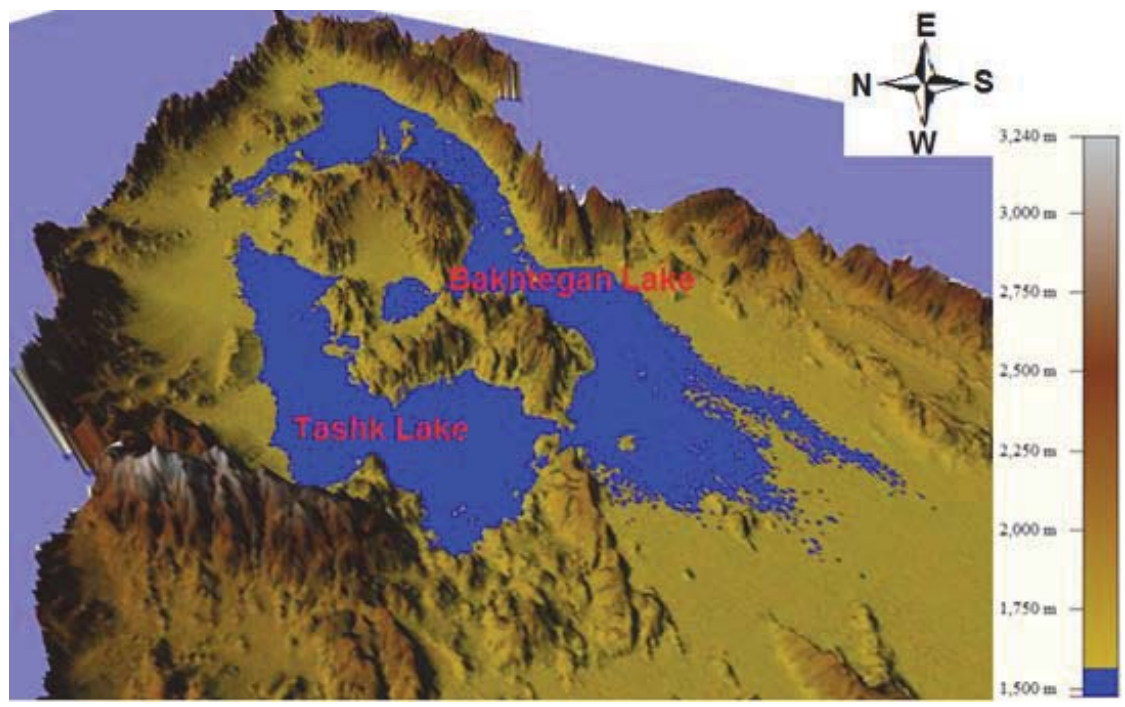

Figure 6: Reconstruction the hydrological relationship between Tashk and Bakhtegan lakes on DEM region.

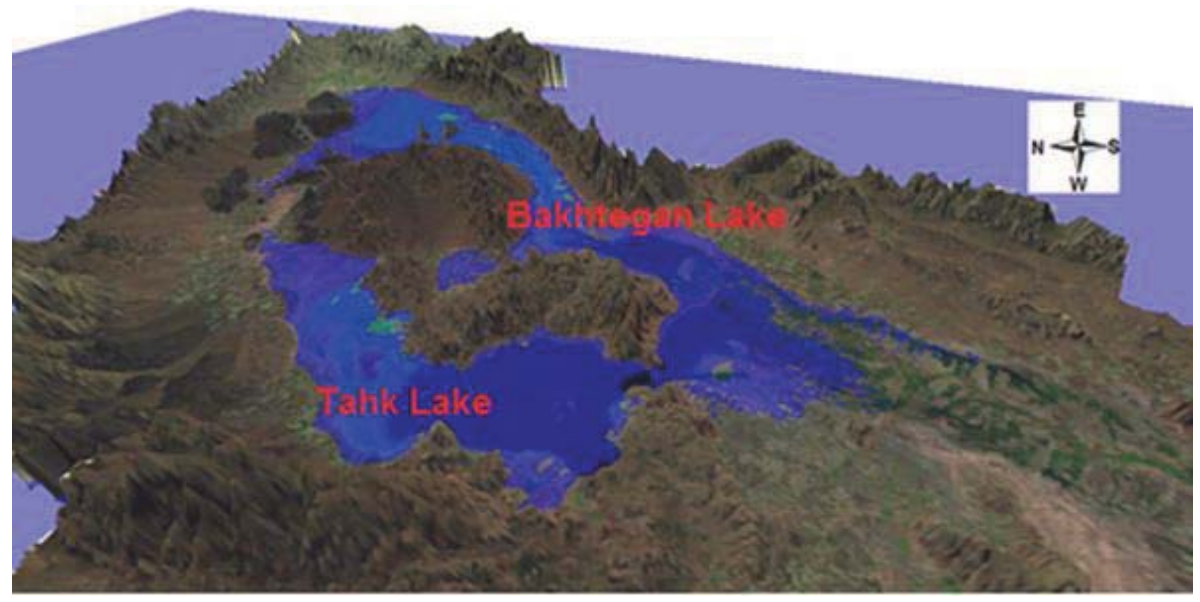

Figure 7: Reconstruction the hydrological relationship between Tashk and Bakhtegan lakes in three dimentional space.

In below longitudinal profile, the effects of unevenness between these two lakes in detachment level of Bakhtegan and Tashk in shown obviously. Another important problem which is obviouse from this profile, was the direction and slope of mentioned lakes so that the area slope was from the Bakhtehan to Tashk lake and the Bakhtegan lake level was higher than Tashk lake, so during the wet years, the hydrological relationship between them based on connected vessles law was satisfied and the Bakhtegan lake level was turned to the Tashk lake, and this trend is continued and finally the environmental balance is resulted. 


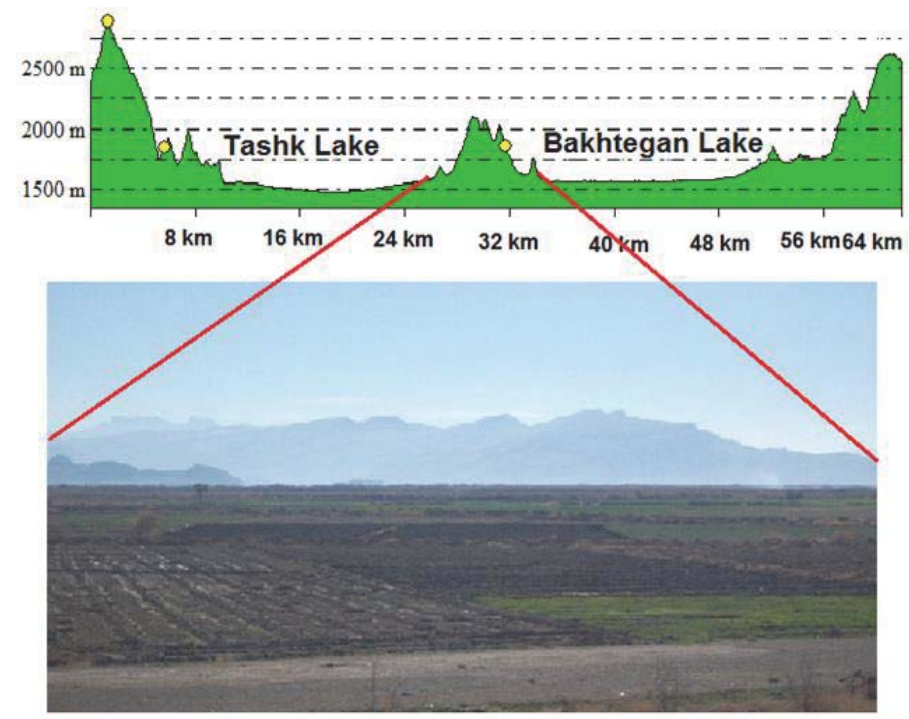

Figure 8: The heights between Tashk and Bakhtegan lakes.

\section{Conclusion}

The Tashk lake water volume and area during the year 2013 A.D was respectively equal to $4087490834360 \mathrm{~m} 3$ and 263/15 km2 and also the Bakhtegan lake water volume and area during the year 2013 A.D was respectively equal to $465193673008 \mathrm{~m} 3$ and $300 / 13 \mathrm{~km} 2$. The mentioned lake area reduced to 688/74 km2 during the studied period, and the water volume had $1093861115494 \mathrm{~m} 3$ reduction. So using the old shore lines modeling of these lakes in higher heights, the hydrological relationship hypothesis between these two lakes based on connected vessles law is satisfied. Than modeling and identification these relationships using the GIS and remote sensing technology was done. Therefore in this place, the importance and efficacy of remote sensing and GIS technology was determined as a useful instrument to determine and detect the hydrological and geometrical relationship between lakes. The results of present study showed that the hydrological relationship between Tashk and Bakhtegan lakes mainly is affected by climatic processes and the precipitation parameter, which with precipitation amount reduction during the past years until now, the water area and volume is reduced obviousely which ultimately their hydrological relationship is detached. Among the effective geomorphological factors to detach the relationship between these two lakes is mainly due to the heights between Tashk and Bakhtegan lakes and secondly the present sediments in valleys present in mentioned lakes entrance which regarding the effect importance is so lower than climatic factors. In the following, because of huge Tashk and Bakhtegan lakes water volume and area and hydrological relationship detachment between them the bio_enviromentalbalance of this region and even in hydrological basin level. Among the obviouse samples, the vast reduction in birds and animals reduction present in the lake ranges and around it in Bakhtegan protected region. Regarding the paleoclimatologicalcondition ,the regional moisture should be mentioned which cause vast droughness and fig and pistacia gardens reduction and making fluvial ranges in drought lakes bed and have important effect in regional pollution.

\section{References}

Singh, A.,1989 ,Digital change detection techniques using remotely sensed data, Int J. R. S.Vol.10,No 6, 989-1003.

eng. P. S., shunji M., Kiyoshi H., Robert L.G. S. Samarakoon,1998,Detection of coast lines of tonle Sap lake in flood season using JERS-1 data for water volume estimation STAR program, Asian Institute of Technology.

Tephen A. K., 2002, A remote sensing and GIS Study of Lont-Term water mass balance lake Jackson, College of Enegineering Science Technology \& Agriculture. Florda, U.S.A.

Seyf, Abd- Allah, 2005,Paleogeomorphological evaluation and analysis of Gaw- khooni playa using the remote sensing and GIS technology, Doctoral thesis, Esfahan University.

Sharifikia, Mohammad, 2010, Investigation the changes in Hamoon lake water level based on remote sensing time series images, Human science educator journal, space programming and investigation, fourth period, NO:3.

Khabbazi, Mostafa, 2013, Paleogeomorphological evaluation and investigation of Dagh- Sorkh desert. Doctoral thesis, Esfahan University. 